\title{
Enhanced master/slave control strategy enabling grid support services and offshore wind power dispatch in a multi-terminal VSC HVDC transmission system
}

\author{
Roberto Sandano \\ Technological University Dublin, roberto.sandano@gmail.com \\ Michael Farrell \\ Technological University Dublin, michael.farrell@tudublin.ie \\ Malabika Basu \\ Technological University Dublin, malabika.basu@tudublin.ie
}

Follow this and additional works at: https://arrow.tudublin.ie/engscheleart2

Part of the Electrical and Computer Engineering Commons

\section{Recommended Citation}

Sandano, Roberto \& Farrell, Michael \& Basu, Malabika. (2017). Enhanced master/slave control strategy enabling grid support services and offshore wind power dispatch in a multi-terminal VSC HVDC transmission system. Renewable Energy. 113. 10.1016/j.renene.2017.07.028.

This Article is brought to you for free and open access by the School of Electrical and Electronic Engineering at ARROW@TU Dublin. It has been accepted for inclusion in Articles by an authorized administrator of ARROW@TU Dublin. For more information, please contact arrow.admin@tudublin.ie, aisling.coyne@tudublin.ie, gerard.connolly@tudublin.ie.

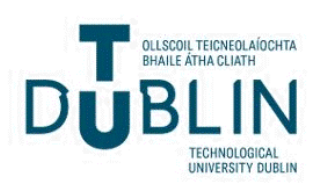




\title{
Enhanced master/slave control strategy enabling grid support services and offshore wind power dispatch in a multi-terminal VSC HVDC transmission system
}

\author{
Roberto Sandano*, Michael Farrell, Malabika Basu \\ School of Electrical and Electronic Engineering, Dublin Institute of Technology (DIT), Ireland
}

\section{A R T I C L E I N F O}

\section{Article history:}

Received 19 September 2016

Received in revised form

9 May 2017

Accepted 6 July 2017

Available online 8 July 2017

\section{Keywords:}

Offshore wind

Multi-terminal dc systems

Enhanced master/slave control

DC voltage control

Frequency support

Grid support services

\begin{abstract}
A B S T R A C T
New high voltage direct current (HVDC) installations are expected to be able to provide stability support to the main synchronous networks to which they are connected. In multi-terminal HVDC (MTDC) schemes incorporating offshore wind farm this issue could be addressed by setting aside a reserve of wind energy by the curtailment of wind turbine generators (WTGs).

This paper proposes a communication-less dc voltage cooperative control strategy for MTDC transmission systems. A grid side converter, the master, and a wind farm are designed to work cooperatively to maintain a stable dc link voltage, facilitating normal power dispatch orders and the provision of frequency support. The proposed control maintains a wind energy reserve and uses a flexible dc link voltage at the master converter. Allowing the local master dc voltage to vary within certain limits encourages the wind farm to participate in dc link voltage control and hence no communication system is required. The master converter automatically assumes control of the dc link voltage in the absence of wind or when the wind reserve is used up.

A four terminal MTDC system comprising one master converter, two active/reactive power converters and one wind farm is studied. The effectiveness of the proposed control strategy is validated through simulation using MATLAB ${ }^{\circledR}$-SIMULINK ${ }^{\circledR}$.
\end{abstract}

() 2017 Elsevier Ltd. All rights reserved.

\section{Introduction}

High Voltage Direct Current (HVDC) connections have been in operation since the 1950s. The vast majority of these are point to point connections and use Line Commutated Converter (LCC) technology. Since the late nineties Voltage Source Converter (VSC) technology has become a feasible choice for HVDC transmission systems [1]. Research is now focused on the development of multiterminal-HVDC (MTDC) system which will collect energy from distant dispersed renewable energy resources and transport this energy to load centres. Although some multi-terminal systems currently exist, they are rare, with two of them using LCC technology (SACOI and Quebec - New England Transmission) and two of them (Nanao and Zhoushan), recently commissioned, using VSC technology.

In point-to-point VSC HVDC connections, typically, one conv-

\footnotetext{
* Corresponding author.

E-mail address: roberto.sandano@gmail.com (R. Sandano).
}

erter station controls the dc link voltage and the other is modulating the active power. Additionally the two converters can control separately the reactive powers at both ends. In MTDC systems the control of the dc voltage is still a focus of research [2-5]. Existing VSC MTDC systems adopt an extension of the point-to-point scheme, having just one converter dealing with the DC voltage control [6] while the other converters in the system operate either in fast active/reactive (PQ) mode or in grid forming mode. The PQ converters control the active and reactive power flows to the grid and the grid forming converters control the voltage magnitude and frequency at an ac busbar. The configuration for a MTDC scheme with only one converter controlling the dc voltage is sometimes associated with the so-called voltage margin method proposed in Ref. [7] which selects a new dc voltage controller when the original reaches its limit of power range and so of regulation.

A notable different method for dc voltage control in MTDC systems is proposed in Ref. [8], the so-called droop control approach. It is an extension of the power frequency droop characteristics adopted for synchronous generators. The main drawback of this control logic is the loss of the exact command of the MTDC 
power flow if a constant droop coefficient is adopted. To change the droop coefficient to match the power needs of the main synchronous network, fast communication between converters is required.

One of the main drivers for the development of several MTDC grids worldwide is the collection of power from dispersed offshore wind farms. In this regard [9] presents different MTDC projects to be implemented in Europe. Several papers such as [8,10,11] apply droop characteristics to dispatch the entire wind energy, produced by the dc connected wind farms, to the grid side converters, according to the droop coefficient adopted.

The recent rapid growth of variable renewable energy resources in the transmission system is driving the introduction of stricter network regulations. In particular [12] states that future HVDC connections in Europe must be able to support the stability of the main synchronous network to which they are connected. Under these new regulations future HVDC converter stations connected to the synchronous grid will be expected to provide the relevant Transmission System Operator (TSO) with a control mode capable of supporting network stability. This will apply whether wind farms are present or not on the MTDC system. This means that each of the grid side converters must be provided with an independent control mode to modulate active and reactive power output to assist in maintaining stable system frequency and voltage.

The requirement for each grid connected converter to be able to provide ancillary services and to dispatch wind energy in a MTDC system containing wind farms can be met by regulating the wind power output. In Refs. $[13,14]$ it has been shown that wind turbine generators (WTGs) are able to increase production above the available wind power by extracting kinetic energy from the rotor. This rotational energy is only available for a short period and a following phase of energy shortage to re-accelerate the rotor is unavoidable. As a result $[15,16]$ state that only WTGs operating in a reduced or curtailed power mode are able to participate effectively in the grid primary frequency regulation. Additionally in Ref. [17] it has been demonstrated that in the short to medium term curtailment can become an optimal economical solution. Different wind power regulation methods have already been adopted by system operators for WTGs connected directly to the ac grid. A comprehensive review is presented in Ref. [18]. All of these methods envisage a difference between the available aerodynamic power and the delivered electrical power when the frequency moves from the optimal.

In this context this paper develops a dc voltage cooperative control scheme between a grid side converter, called the master, and a dc connected curtailed wind farm. The dc network voltage is allowed to fluctuate in between specific limits under the supervision of the master converter. Within this dc voltage range the master converter operates in a slow PQ control mode as a result of the cascaded PI structure used for the master controller. The standard control scheme used on all the other grid side converters allows them to be operated in fast $\mathrm{PQ}$ mode, i.e. able to deliver frequency and voltage regulation. An energy reserve, in the form of curtailed WTGs on the wind farm, allows the wind farm to participate in the stabilization of the network dc voltage. The wind farm control scheme responds to the dc link voltage fluctuations hence no fast communication system is needed.

The remaining sections of the paper are organized as follows: Section 2 describes the topology and control method employed for the wind farm, master and PQ converters. Section 3 provides the simulation results for two operating scenarios: Case I, considers normal operation where a wind power reserve is maintained on the wind farm and the energy is dispatched by the grid side converters according to market requirements and, Case II, considers an emergency situation where the wind energy reserve is deployed for meeting frequency support requests. The analysis of the simulation results and conclusion are presented in the last Section 4.

\section{MTDC system description}

A four terminal MTDC system is considered consisting of one dc connected offshore wind farm and three converters connected to the grid. The three grid side converters consist of two standard PQ converters and one master converter station. Fig. 1 shows the model of MTDC system, symmetrical monopole connection at \pm $200 \mathrm{kV}$ with three-level converters are used. Converter dc side equivalent capacitance is sized at $2 \mathrm{mF}$ and cable connections are modelled as distributed parameter transmission lines, distances and cable details are given in Fig. 1.

HVDC PQ converter stations are usually controlled with a standard voltage oriented control technique [19], capable of fast power ramp in the order of $1 \mathrm{GW} / \mathrm{s}$. Here current references $I_{d}^{*}$ and $I_{q}^{*}$ for both the PQ converters are directly linked to the reference values of active and reactive power $P_{g}^{*}$ and $Q_{g}^{*}$ specified by the relevant TSO, refer to Fig. 2 for details. The $d$ - and $q$-axis current PI regulators are usually called inner current controllers and they show very fast response.

\subsection{Wind farm}

An offshore wind farm connected through an HVDC connection to the main network is an ac offshore grid driven by its converter station in grid-forming mode control, i.e. controlling voltage magnitude and frequency as an ideal voltage source. The wind farm model is composed of ninety six WTGs rated at 3.3MVA each at the base wind speed of $9.4 \mathrm{~m} / \mathrm{s}$, giving a total rated generated wind power of $288 \mathrm{MW}$. Squirrel cage induction generators (SCIG) in fixed speed wind turbine configuration were chosen for simplicity, in fact the base wind speed corresponds to an average value of the real wind speed measurement used in the next simulations. Table 1 gives the individual WTG details.

The wind turbine coupled to each SCIG is as per the standard described in Ref. [20]. The mechanical torque $T_{m}$ driving the

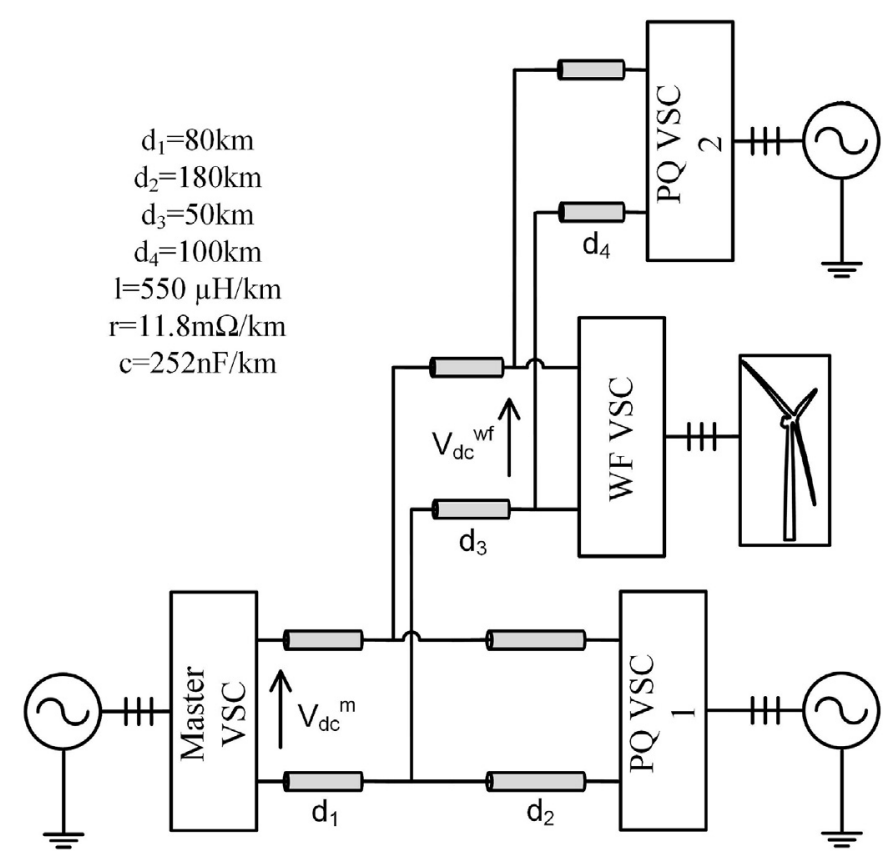

Fig. 1. Four terminals used on the present simulation. 


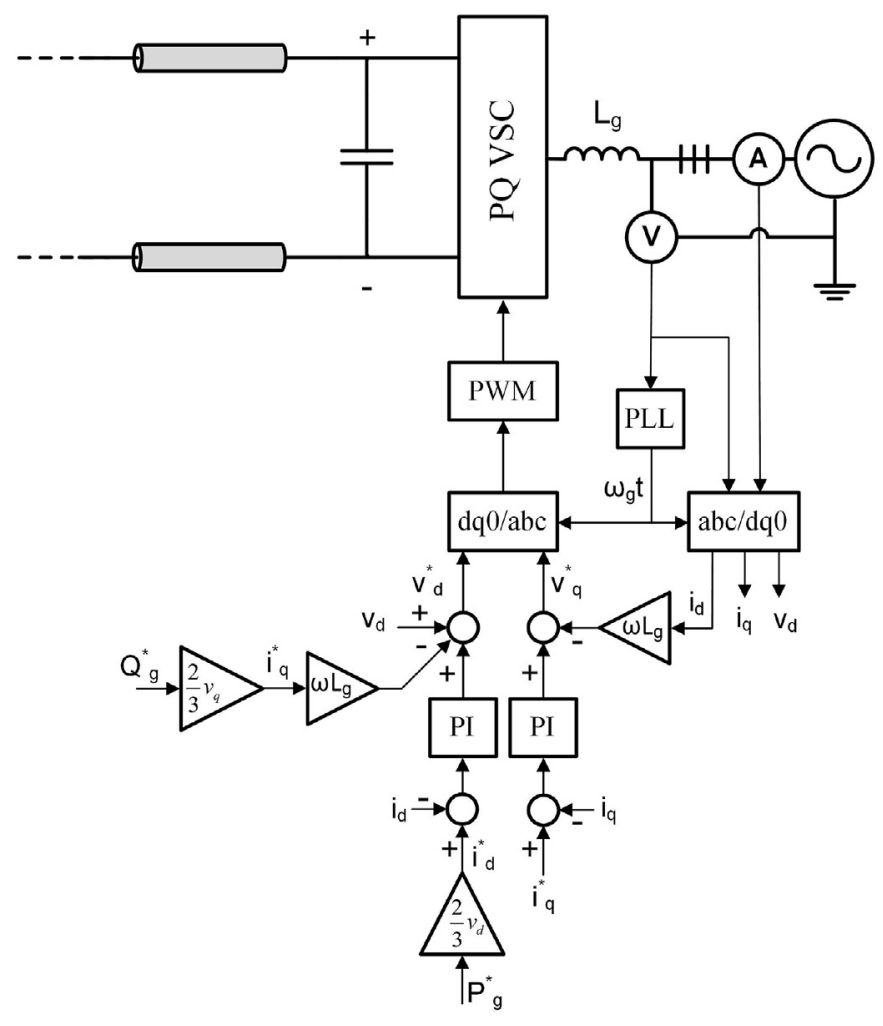

Fig. 2. PQ grid side converter modelling and control, here only inner current controllers are needed.

electrical machine is given by:

$T_{m}=\frac{P_{m}}{\omega_{r}}=\frac{\rho A v^{3} C_{p}}{2 \omega_{r}}$

where $P_{m}$ is the mechanical power, $\omega_{r}$ is the rotational speed of the rotor, $\rho$ is the air density, $v$ the wind speed and $C_{p}$ the power coefficient described as:

$C_{p}=c_{1}\left(\frac{c_{2}}{\lambda_{i}}-c_{3} \beta-c_{4}\right) e^{-\frac{c_{5}}{\lambda_{i}}}+c_{6} \lambda$

where $\beta$ is the pitch angle and $\lambda_{i}$ is a function of $\lambda$, the tip speed ratio.

Fixed speed turbine generators, such as SCIGs, use a high speed shaft coupled to the electrical machine which is connected via a gearbox to a low speed shaft connected to the turbine rotor. On a transient simulation sophisticated modelling of the shaft and the gearbox as presented in Ref. [21] would be needed. In our case a power system dynamics simulations is considered and then the

Table 1

WTG parameters.

\begin{tabular}{lll}
\hline Parameters & Magnitude & Units \\
\hline Nominal power @ 9.4 m/s & 3.3 & MVA \\
Nominal voltage & 575 & $\mathrm{~V}$ \\
Stator resistance $\left(R_{S}\right)$ & 0.48 & $\mathrm{~m} \Omega$ \\
Stator inductance $\left(L_{s}\right)$ & 0.033 & $\mathrm{mH}$ \\
Rotor resistance $\left(R_{r}^{\prime}\right)$ & 0.43 & $\mathrm{~m} \Omega$ \\
Leakage inductance $\left(L_{l r}^{\prime}\right)$ & 0.047 & $\mathrm{mH}$ \\
Magnetizing inductance $\left(L_{m}\right)$ & 1.8 & $\mathrm{mH}$ \\
Pole pairs $(p)$ & 3 & \\
Inertia constant $(H)$ & 5.1 & $\mathrm{~s}$ \\
\hline
\end{tabular}

rotor is modelled as a lumped mass using the well known swing equation:

$\omega_{r}=\frac{1}{2 H} \int\left(T_{m}-T_{e}\right) d t$

where $T_{e}$ is the electrical torque and $\mathrm{H}$ the inertia constant.

This provides the possibility of adjusting the performance coefficient $C_{p}$ versus tip speed ratio $\lambda$ graph of the turbine characteristic including the effect of the change of the pitch angle. Fig. 4 shows the effects of wind speed and pitch angle variations on the mechanical power output of the used turbine.

As mentioned earlier in this study the WTGs are curtailed to maintain a wind power reserve. With SCIGs it is only possible to curtail the WTG output through pitch regulation because the rotational speed is set by the offshore grid frequency. Recent improvements in the maximum allowed pitch slew rate in modern WTG show that it is usually in the range of $8-10^{\circ} / \mathrm{s}[22,23]$. The main reason for the improvement in pitch dynamics has been due to the need to be able to reduce power output rapidly in emergency situations. In fact mechanical brakes for the rotor of MW-class WTG cannot be used for rapidly reducing power output. It is reported in Ref. [24] that in 2009 for German offshore installations active power output has to be reduced at a rate of $25 \%$ per second.

The wind farm power output $P^{w f}$ is regulated, up and down by making use of the wind farm reserve. When the local dc voltage at the wind farm converter station $V_{d c}^{w f}$ moves from the rated $\tilde{V}_{d c}=400 \mathrm{kV}$ a standard PI control technique is used to control the local dc voltage through the actuation of the pitch angle $\beta$ of each WTGs as given by:

$\beta=k_{p, \beta}\left(V_{d c}^{w f}-\tilde{V}_{d c}\right)+k_{i, \beta} \int\left(V_{d c}^{w f}-\tilde{V}_{d c}\right) d t$

The obtained $\beta$ angle, computed on the offshore converter

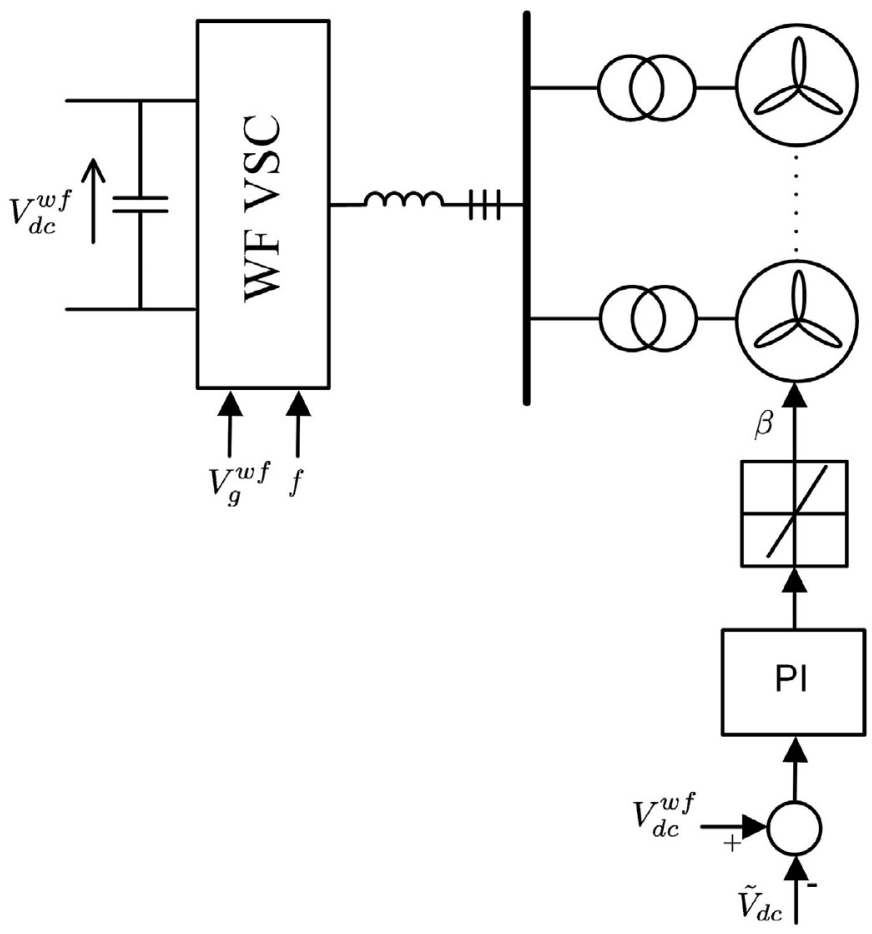

Fig. 3. Wind farm converter in grid forming mode control and local dc voltage control through blade pitch actuation. 


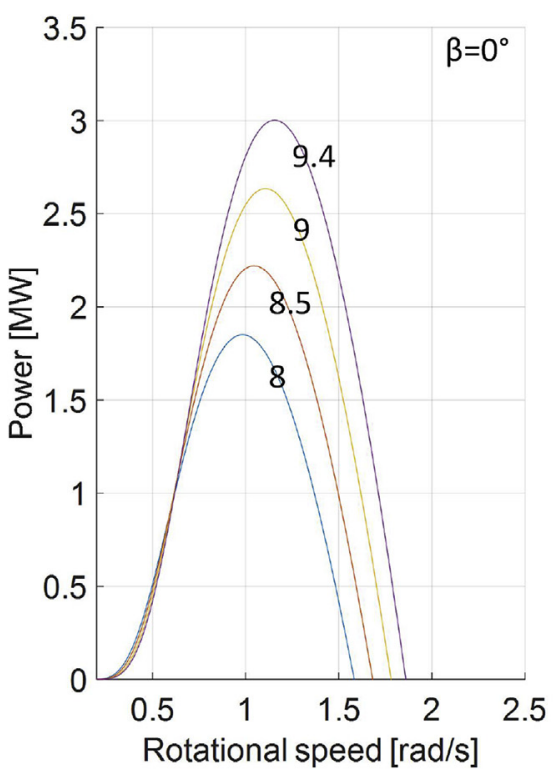

(a)

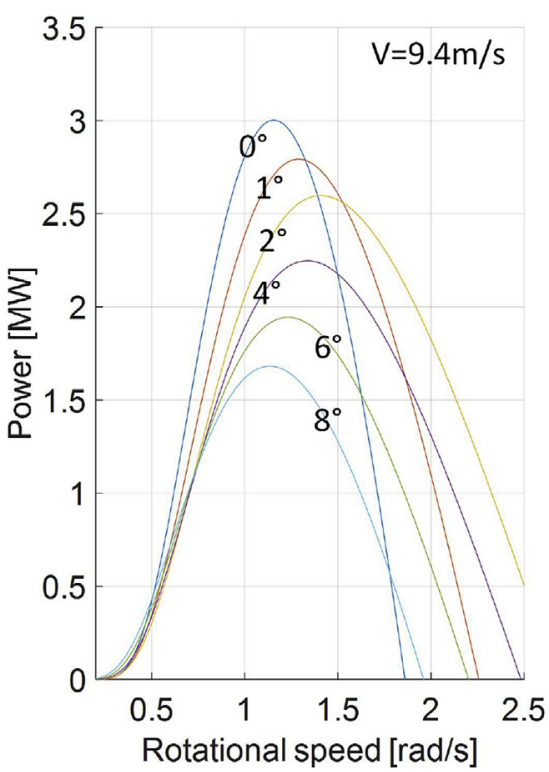

(b)

Fig. 4. Power curve as a function of the rotational speed, (a) in relation to wind speed with $\beta=0$ and (b) in relation to pitch variations at $9.4 \mathrm{~m} / \mathrm{s}$ wind speed.

station, needs to be communicated to each WTG through a local offshore communication system. This kind of local communication network is easily obtainable using commercially available composite offshore ac cables with optical fibre. Another advantage of an offshore local network is the collection of WTG on-line data to allow the manufacturer to remotely check the turbine status in order to avoid malfunctioning.

As visible in Fig. 3 the dynamics of the pitch actuator is limited by a maximum rate of change, set for the next simulation at $\pm 7^{\circ} / \mathrm{s}$.

\subsection{Enhanced master control system design}

The proposed master converter control strategy allows control of the active power output $P_{g}^{m}$ by deviating the local dc link voltage reference $V_{d c}^{m^{*}}$. The control logic adopted derives from the standard dc voltage/reactive power control as shown in Refs. [25,26]. In order to achieve active power control, an additional outer loop, hereafter called the power loop, is added as shown in Fig. 5 and given by:

$V_{d c}^{m^{*}}=\tilde{V}_{d c}+k_{p, P}\left(P_{g}^{m}-P_{g}^{m^{*}}\right)+k_{i, P} \int\left(P_{g}^{m}-P_{g}^{m^{*}}\right) d t$

where $P_{g}^{m}$ is the power dispatched at the master converter terminal (generator convention), $P_{g}^{m^{*}}$ is the reference value as requested by the relevant TSO and the feedforward rated dc voltage $\tilde{V}_{d c}$ ensures the local dc voltage $V_{d c}^{m}$ deviates around $\tilde{V}_{d c}$.

Active power output and dc voltage control are two conflicting objectives and indeed the power loop is needed to shift the local dc voltage up and down from the rated $\tilde{V}_{d c}=400 \mathrm{kV}$, to indirectly communicate to the WTGs to inject more or less power. The dc voltage deviation at the master converter is set at $\tilde{V}_{d c} \pm 5 \%$. This value was chosen by assuming that the other MTDC converters connected to the system would not be disturbed by a corresponding deviation of their modulation indices. Similarly, the commonly allowed ac voltage variation at the transmission level, where HVDC installation would normally be connected, is at least $\pm 5 \%$.

The dc voltage limitation locally on the master converter terminal ensures that a given power reference $P_{g}^{m^{*}}$ from the TSO is only allowed if the local dc voltage $V_{d c}^{m}$ is within the range. An antiwindup on the power loop ensures a prompt recovery of the PQ operability of the master converter once the available and the delivered powers match each other. Considering the above

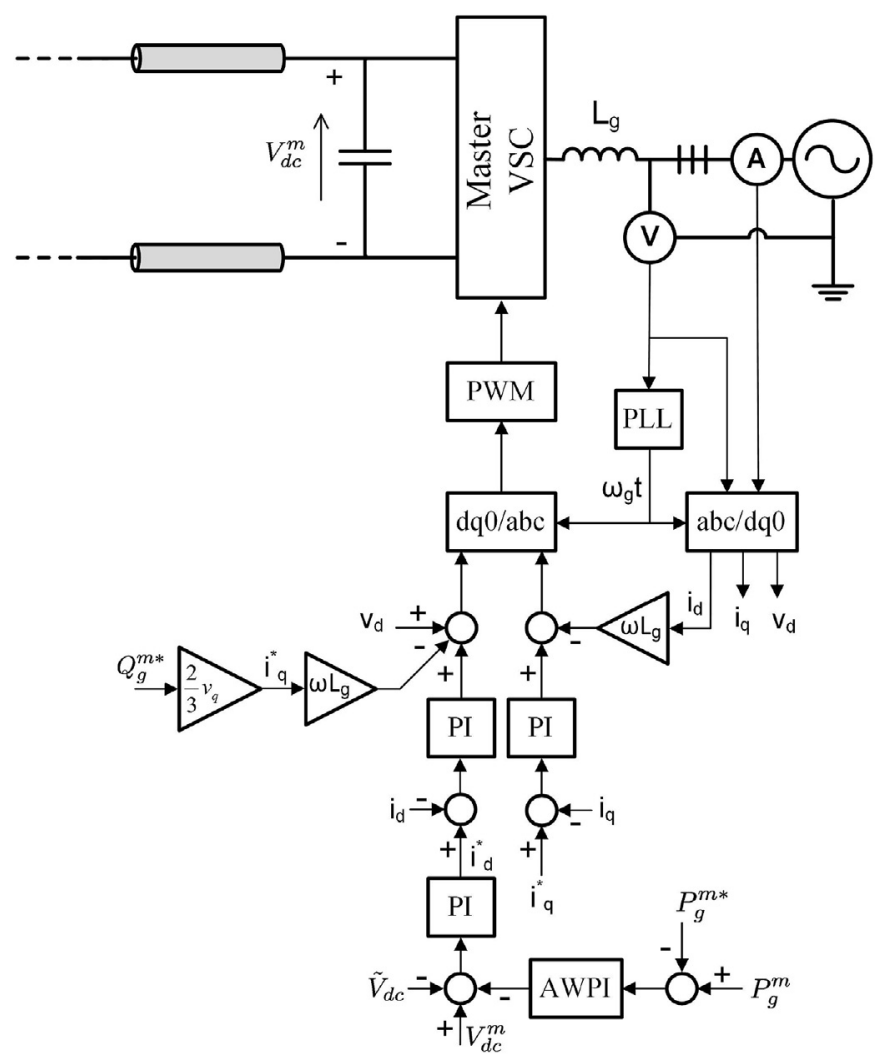

Fig. 5. Master converter control, the anti-windup PI (AWPI) controller is bounded at $\tilde{V}_{d c} \pm 5 \%$. 
description a three zone operation range results for the master converter as follows:

- Zone I: $380 \mathrm{kV}<V_{d c}^{m}<420 \mathrm{kV}$, master in PQ mode When the local dc voltage at the master terminal is within zone I a percentage of the available wind energy is curtailed by pitch angle control with the bulk of the wind energy being dispatched at the master and PQ terminals, in accordance with market requirements. In this zone the master converter controls the power output analogously, but slower, to a PQ converter, dispatching a defined amount of active and reactive power set by the TSO. The local dc voltage at the master converter terminal $V_{d c}^{m}$ finds an equilibrium within the chosen range of $\tilde{V}_{d c} \pm 5 \%$ because the integral part $k_{i, \beta}$ of the pitch angle $\beta$ controller nullifies the error $V_{d c}^{w f}-\tilde{V}_{d c}$. In this way it is the wind farm which controls the dc voltage although the master converter ensures the voltage does not exceed a specific range. As a result in zone I the grid side converters are capable of providing a predefined amount of reserve in the form of an ancillary service. However the slew rate for the grid side converter power injections depend upon the converter topology and the control logic adopted, the wind farm and the reserve dimensions, and finally the WTG slew power rate capability.

- Zone II: $V_{d c}^{m}=380 \mathrm{kV}$ lower threshold, deficit in wind power reserve

When the local master converter dc voltage $V_{d c}^{m}$ reaches the lower threshold $\tilde{V}_{d c}-5 \%=380 \mathrm{kV}$ the master converter assumes full control of the dc voltage and maintains it at $380 \mathrm{kV}$. At this point the wind farm is dispatching the maximum available power because the reference for the pitch angle $\beta$ would be driven to $0^{\circ}$ by its PI controller as given in Eq. (4). In this zone the master converter does not fulfil the active power delivery request, because the available power is not enough. Depending on the overall capacitance of the dc network and on the prompt response of the WTGs, an ac frequency regulation intervention could lead the dc voltage reaching the lower threshold forcing the master terminal to partially take on the frequency regulation burden. However only the continuity of $V_{d c}^{m}$ at the lower threshold signals that either an abnormal forecast error of the wind energy has occurred or there is a total absence of wind power reserve because of low wind speed.

- Zone III: $V_{d c}^{m}=420 \mathrm{kV}$, upper limit zone

Similar to zone II when the local master dc voltage $V_{d c}^{m}$ reaches the upper threshold $\tilde{V}_{d c}+5 \%=420 \mathrm{kV}$ the power loop on the master converter is bypassed and the master converter maintains the dc voltage at the upper limit of $420 \mathrm{kV}$. To reach the upper threshold implies one or more of the grid side converters are exceeding the down-regulation of the power output. Contrary to the zone II, upon reaching the upper bound the master converter is forced to deliver more power than its reference $P_{g}^{m^{*}}$. However only the continuity of $V_{d c}^{m}$ at the upper level would lead to the complete shut down of the wind farm because of the pitch regulator continuous integration. This possibility can be easily avoided setting a maximum pitch angle $\beta_{\max }$ corresponding to a minimum wind farm power output $P_{\min }^{w f}$. In fact a wind farm start up could take a considerable time. To conclude applying the energy exchange close to real time rules, as recently introduced in intra-day markets, would likely avoid the operation in Zone III. As a result the simulation section of this paper will not consider operation in this zone.

The adopted master control technique uses two outer loops in cascade on the current $d$-axis. An outer controller must be tuned with a relative response time (RRT) slower than the inner controller to avoid interaction [27]. As a result the PQ converter, with only inner controllers, can dispatch power at a faster rate than the master converter both in case of frequency regulation and in case of power re-distribution between the terminals. In the next simulation different power ramps are then adopted for the reference values of the active power dispatched by the grid side converters.

A summary of the operability of the proposed MTDC is provided in Table 2.

\section{Simulation}

Two different scenarios are presented starting from an equilibrium setpoint with a wind power reserve of about $100 \mathrm{MW}\left(\beta \approx 8^{\circ}\right)$ and $150 \mathrm{MW}\left(\beta \approx 11^{\circ}\right)$, as shown in Figs. 6 and $7 \mathrm{a}$-(iii), respectively. As mentioned, the maximum rate of change of pitch is adopted conservatively to $\pm 7^{\circ} / \mathrm{s}$. The wind speed data shown in Figs. 6 and $7 a-(i v)$ is taken from real measurement recorded at a DIT wind speed measurement station at a sampling rate of $10 \mathrm{~Hz}$.

The simulations include both normal market-based operations, as shown in Fig. 6, and sudden (not previously agreed) frequency regulation operations, as shown in Fig. 7. Normal market-based procedures consist of power flow redistribution between the HVDC converter stations connected to different points of the main grid. On the other hand frequency regulation operations are in this case addressing ac grid frequency rapid changes referred in the form of grid side converter active power output rapid changes. Power ramp orders of $\pm 1200 \mathrm{MW} / \mathrm{s}$ are used in the simulations when the PQ converters change their power output, either for power redistribution or for frequency response. Differently, when the master converter is involved in power variations a different power ramp of $\pm 300 \mathrm{MW} / \mathrm{s}$ is used because of the cascaded PI structure of the master d-axis controller.

Section 3.1 comments on the simulation results for normal power redistribution operations in which the produced power by the wind farm is dispatched according to market rules by the three grid side converters. This scenario is provided to show that the presented MTDC system is able to fulfil all the market-based requests, i.e. to sell offshore wind energy and to transmit power to/from dispersed network points.

Section 3.2 shows a series of unpredicted active power requests for frequency support by both PQ converters and hence a ramp rate of $\pm 1200 \mathrm{MW} / \mathrm{s}$ is used. The initial reserve of power within the wind farm is exhausted during this simulation, so the master converter loses the active power control reaching the lower dc voltage threshold. This second scenario shows that the stability of the MTDC dc voltage is maintained even under severe demands of frequency up-regulation.

The operation of the multi-terminal VSC-HVDC transmission system is tested through simulations in MATLAB ${ }^{\mathbb{Q}}$-SIMULINK ${ }^{\mathbb{B}}$ using SimPowerSystems ${ }^{\mathrm{TM}}$ library.

\subsection{Case I, normal operation}

In normal operation the local dc voltage at the master converter

Table 2

Summary of operability conditions of the master converter and the wind farm with reference to zones described in Sec. 2. Details in text.

\begin{tabular}{llll}
\hline & \multicolumn{2}{l}{$V_{d c}^{m}$ in Zone } & \\
\cline { 2 - 4 } & $\mathrm{I}$ & II & III \\
\hline dc voltage control & wind farm & master & master \\
master P control & Yes & No & No \\
$V_{d c}^{m^{*}}$ & Eq. (5) & $\tilde{V}_{d c}-5 \%$ & $\tilde{V}_{d c}+5 \%$ \\
pitch angle $\beta$ & Eq. (4) & 0 & max \\
\hline
\end{tabular}



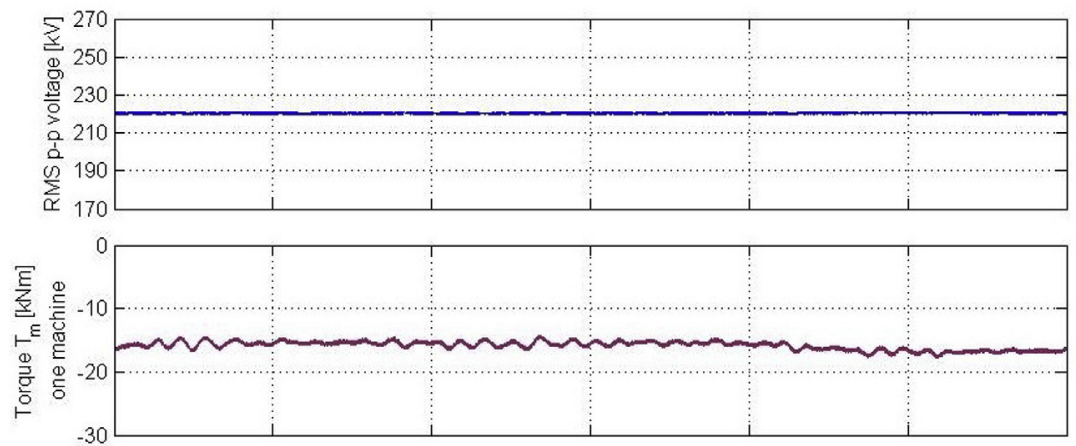

(ii)
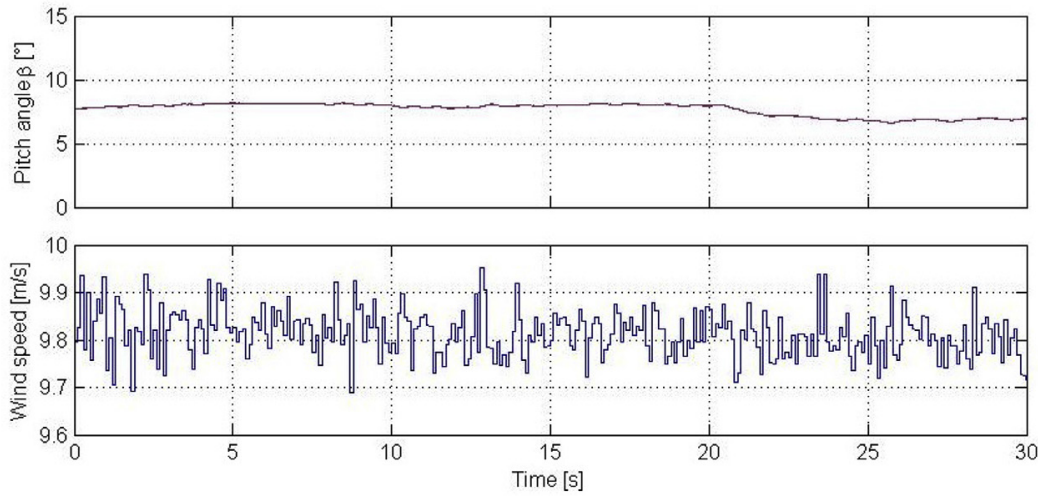

(a) Wind farm quantities during normal operation scenario. (i) ac RMS p-p voltage on wind farm offshore grid (ii) torque of one machine (iii) pitch angle $\beta$ and (iv) wind speed
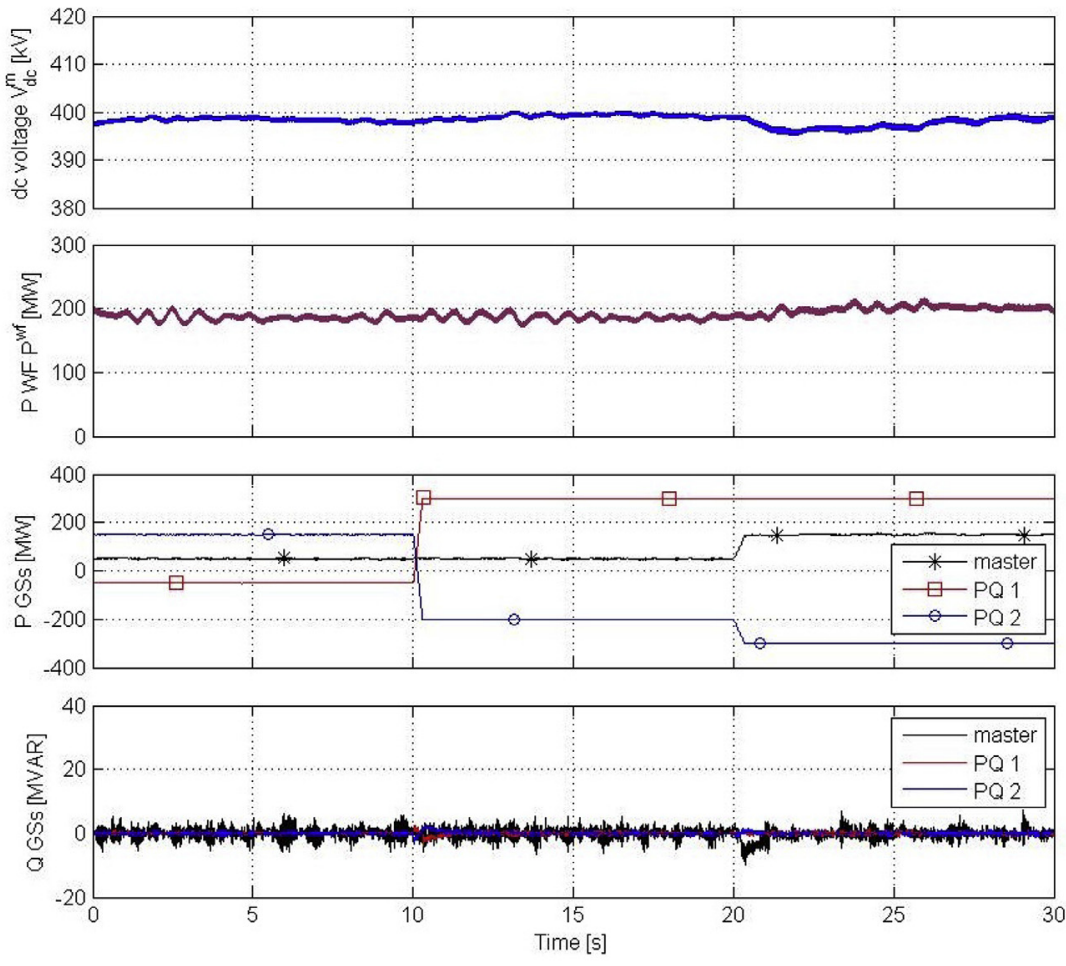

(b) dc link and grid sides quantities. (i) local dc voltage at master converter $V_{d c}^{m}$ (ii) injected active power by wind farm (iii) active power dispatched by grid sides (iv) reactive power dispatched by grid sides

Fig. 6. Normal operation scenario showing power redistribution between two PQ converters at 10 s and master-PQ2 at 20 s. 

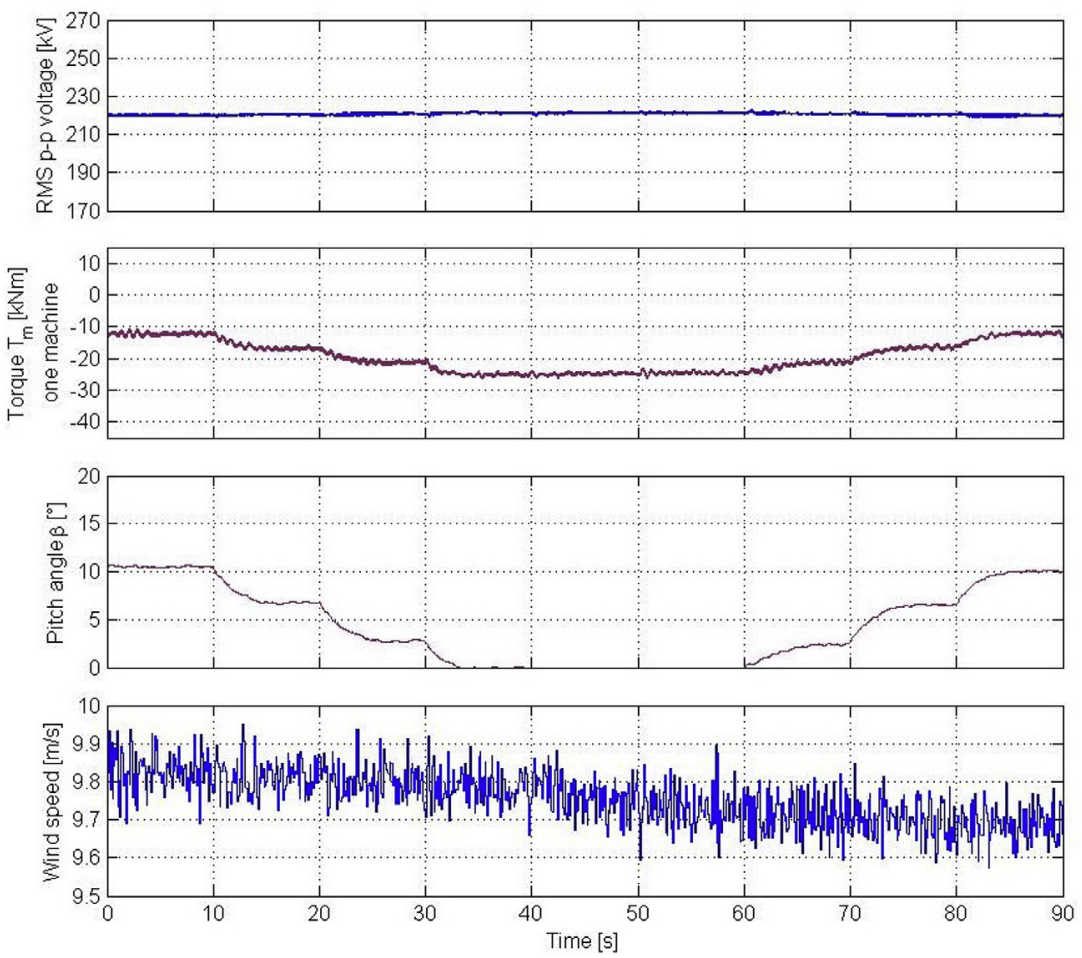

(a) Wind farm quantities during reserve usage scenario. (i) ac RMS p-p voltage on wind farm offshore grid (ii) torque of one machine (iii) pitch angle $\beta$ and (iv) wind speed
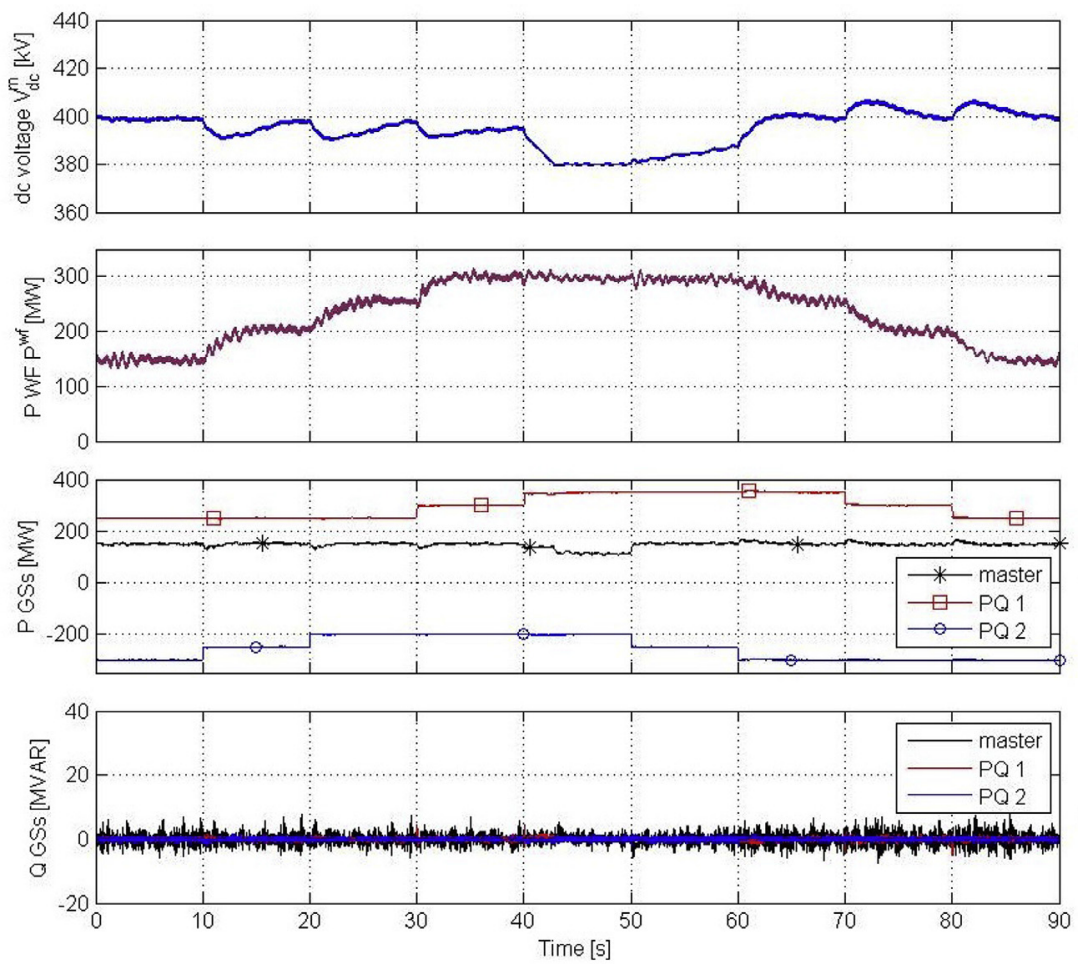

(b) dc link and grid sides quantities. (i) local dc voltage at master converter $V_{d c}^{m}$ (ii) injected active power by wind farm (iii) active power dispatched by grid sides (iv) reactive power dispatched by grid sides

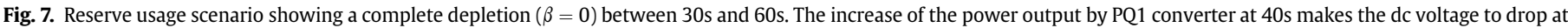
the lower threshold and the master to lose the active power control. 
terminal $V_{d c}^{m}$ remains within Zone I as described in Section 2.2. As explained above a spinning reserve of about $100 M W\left(\beta \approx 8^{\circ}\right)$ is maintained comprehensively on all the WTGs. The operations in this simulation scenario have to be thought as market-based so the wind reserve is used only to adjust power mismatches due mainly to wind speed variations and different power losses on the connections. The simulation commences with the master converter dispatching $50 \mathrm{MW}$, converter PQ1 dispatching -50 MW and converter PQ2 dispatching $150 \mathrm{MW}$.

Fig. 6 shows the complete results of Case I simulation with wind farm quantities in Fig. 6a and dc voltage and grid power flows in Fig. 6b. Fig. 6a-(i) shows the offshore ac grid voltage $V_{g}^{w f}$ controlled at $220 \mathrm{kV}$ whereas Fig. 6a-(ii) shows the electromagnetic torque of one machine. Pitch angle $\beta$ and wind speed complete Fig. 6a. Fig. 6b-(i) displays the local dc voltage at the master converter $V_{d c}^{m}$ and Fig. 6b-(ii) shows the dispatched power by the wind farm $P$ wf. Fig. 6b-(iii) shows the active power delivered by the three grid side converters with the two power redistribution operations. At 10 s a $350 \mathrm{MW}$ power exchange between the two PQ converters at a ramp rate of $\pm 1200 \mathrm{MW} / \mathrm{s}$ occurs. As expected the dc voltage does not show any relevant fluctuations and also the pitch angle $\beta$ remains steady. At 20s a new power exchange of $100 \mathrm{MW}$ between the master and a PQ converter occurs. This time the ramp rate is \pm $300 \mathrm{MW} / \mathrm{s}$ being involved the master converter. There is a minor dc voltage deviation, visible at the instance of this second power exchange. This is needed to allow the active power to change according to Eq. (5). Consequently the wind turbine pitch angle $\beta$ deviates smoothly to follow the dc voltage until a new equilibrium is reached. The difference between the initial and the final steady state pitch angles responds to different losses occurring on the dc connections and different wind speed. Finally Fig. 6b-(iv) shows the reactive powers delivered by each of the grid side converters. The three reference values are fixed at zero to provide unity power factor operation.

\subsection{Case II, shortage of reserve}

Case II shows how the developed dc voltage cooperative control technique responds in the case of sudden requests of active power totalling a magnitude larger than the wind power reserve. As a result this scenario simulates the total consumption of the wind power reserve in response to unexpected frequency regulation requests. Two successive power injections of $50 \mathrm{MW}$ occurring at 10 s intervals for each of the PQ converters are considered in this simulation.

As mentioned above the initial wind power reserve of about $150 \mathrm{MW}\left(\beta \approx 11^{\circ}\right)$ is obtained by curtailing the WTGs output through pitch angle regulation. A series of four successive active power increments by the PQ converters are occurring between 10s and 40 s, see Fig. 7b-(iii), those are at a ramp rate of $\pm 1200 \mathrm{MW} / \mathrm{s}$. As visible in Fig. 7a-(iii) the pitch angle $\beta$ decreases at every power increment following the local dc voltage $V_{d c}^{w f}$ at the wind farm terminal. In the time range between 30 s and 40 s the power reserve is almost completely used up so at the fourth power increment at 40 s the dc voltage starts to decrease linearly reaching the lower threshold. Once the dc voltage reaches the lower bound the master converter bypasses automatically the power loop showing a drop on its power output in order to keep the dc voltage constant at $380 \mathrm{kV}$ (zone II). Only the power step to decrease the injected power of converter PQ2 at 50s triggers the master converter to return to Zone I, i.e. the available power is enough to recharge the dc connections. Subsequent power steps in converters PQ1 and PQ2 show the response of the wind turbine pitch angle control as PQ1 and $\mathrm{PQ} 2$ return to their starting points.

Throughout this second simulation the active power reference of the master converter $P_{g}^{m^{*}}$ is fixed at $150 \mathrm{MW}$ and indeed the actual measured power $P_{g}^{m}$ deviates from the reference only between $40 \mathrm{~s}$ and $50 \mathrm{~s}$ when the dc voltage $V_{d c}^{m}$ is locked at the lower threshold. As mentioned above this second scenario is not concerned with market based power redistribution but with regulation operations. Hence the final stage of simulation over 80s resumes the initial power flow in all the three grid side converters even if the wind speed is slightly lower.

\section{Conclusion}

A novel technique for dc voltage regulation on a MTDC transmission system consisting of a master converter, two PQ converters and a wind farm that does not require any communication link has been demonstrated. An outer power loop on the master converter controller and a pitch blade controller have been developed to cooperatively use a reserve of wind power to maintain a stable dc link voltage. The control system proposed allows the wind energy to be dispatched at the grid side converters under normal market rules and also facilities ac grid support services. The master converter, because of its cascaded controller design, operates at a slightly slower ramping rate than a standard PQ converter. However the design of a master converter controller ensures the stability of the MTDC system dc voltage even when the wind power reserve is used up, or indeed when no wind energy is available.

In future implementations of MTDC networks collecting renewable energy, in competitive energy markets, it is very likely that the grid connection points will be expected to provide an array of grid support services. The overall control scheme should be flexible, in the sense of being able to cope with sudden changes in demand without spreading the burden to other grid connection points. However the infrastructure itself cannot rely on a fast communication system. As a result the participation of the renewable energy sources in providing ancillary services to the grid point connections looks unavoidable. In this regard a recent European Wind Energy Association (EWEA) position paper [28] on priority dispatch for wind energy suggests that this will not be needed in mature markets. In fact it is anticipated that voluntary curtailment must be understood as an ancillary service in terms of providing downward reserve capacity or balancing energy, that will enable the system operators to define appropriate rules and share cost calculation.

\section{References}

[1] SCB4 committee of CIGRE, VSC Transmission, TB 2692005 SC B4 WG B4.37, 2005.

[2] L. Xu, L. Yao, DC voltage control and power dispatch of a multi-terminal HVDC system for integrating large offshore wind farms, IET Renew. Power Gener. 5 (3) (May 2011) 223-233.

[3] W. Li, G. Shi, X. Cai, N. Li, A novel dc voltage control strategy for multiterminal HVDC system with offshore wind farms integration, in: 2014 International Power Electronics and Application Conference and Exposition, Nov 2014, pp. 1110-1115.

[4] L. Xu, J. Rafferty, Y. Wang, G. Xu, MTDC systems for frequency support base on dc voltage manipulation, in: International Conference on Renewable Power Generation (RPG 2015), Oct 2015, pp. 1-6.

[5] E. Prieto-Araujo, A. Egea-Alvarez, S. Fekriasl, O. Gomis-Bellmunt, DC voltage droop control design for multi-terminal HVDC systems considering ac and dc grid dynamics, in: 2016 IEEE Power and Energy Society General Meeting (PESGM), July 2016, 1-1.

[6] X. Li, Z. Yuan, J. Fu, Y. Wang, T. Liu, Z. Zhu, Nanao multi-terminal vsc-hvdc project for integrating large-scale wind generation, in: 2014 IEEE PES General Meeting - Conference Exposition, July 2014, pp. 1-5.

[7] T. Nakajima, S. Irokawa, A control system for hvdc transmission by voltage sourced converters, in: 1999 IEEE Power Engineering Society Summer 
Meeting. Conference Proceedings (Cat. No.99CH36364), vol. 2, 1999, pp. $1113-1119$.

[8] L. Xu, L. Yao, M. Bazargan, De grid management of a multi-terminal hvdc transmission system for large offshore wind farms, in: 2009 International Conference on Sustainable Power Generation and Supply, April 2009, pp. 1-7.

[9] European Network of Transmission System Operators for Electricity ENTSO-E. 10-year Network Development Plan 2014, 2014.

[10] Shu Zhou, Jun Liang, J.B. Ekanayake, N. Jenkins, Control of multi-terminal vschvdc transmission system for offshore wind power generation, in: 2009 44th International Universities Power Engineering Conference (UPEC), Sept 2009, pp. $1-5$.

[11] Oriol Gomis-Bellmunt, Jun Liang, Janaka Ekanayake, Nicholas Jenkins, Voltagecurrent characteristics of multiterminal hvdc-vsc for offshore wind farms, Electr. Power Syst. Res. 81 (2) (2011) 440-450.

[12] The European Commission, Commission regulation (EU) 2016/1447, Off. J. Eur. Union (26 August 2016).

[13] M. Juelsgaard, J. Bendtsen, R. Wisniewski, Utilization of wind turbines for upregulation of power grids, IEEE Trans. Ind. Electron. 60 (7) (July 2013) $2851-2863$

[14] G.C. Tarnowski, P.C. Kjar, P.E. Sorensen, J. Ostergaard, Variable speed wind turbines capability for temporary over-production, in: 2009 IEEE Power Energy Society General Meeting, July 2009, pp. 1-7.

[15] P.C. Kjaer, R. Lrke, G.C. Tarnowski, Ancillary services provided from wind power plant augmented with energy storage, in: 2013 15th European Conference on Power Electronics and Applications (EPE), Sept 2013, pp. 1-7.

[16] R.G. de Almeida, J.A. Pecas Lopes, Participation of doubly fed induction wind generators in system frequency regulation, IEEE Trans. Power Syst. 22 (3) (Aug 2007) 944-950.

[17] Henrik Klinge Jacobsen, Sascha Thorsten Schrder, Curtailment of renewable generation: economic optimality and incentives, Energy Policy 49 (2012) 663-675. Special Section: Fuel Poverty Comes of Age: Commemorating 21 Years of Research and Policy.

[18] Iigo Martinez de Alegra, Jon Andreu, Jos Luis Martn, Pedro Ibaez, Jos Luis
Villate, Haritza Camblong, Connection requirements for wind farms: a survey on technical requirements and regulation, Renew. Sustain. Energy Rev. 11 (8) (2007) 1858-1872.

[19] M. Liserre, A. Dell'Aquila, F. Blaabjerg, An overview of three-phase voltage source active rectifiers interfacing the utility, in: 2003 IEEE Bologna Powe Tech Conference Proceedings, vol. 3, June 2003, p. 8.

[20] S. Heier, Grid Integration of Wind Energy: Onshore and Offshore Conversion Systems, Wiley, 2014

[21] S.M. Muyeen, M.H. Ali, R. Takahashi, T. Murata, J. Tamura, Y. Tomaki, A. Sakahara, E. Sasano, Comparative study on transient stability analysis of wind turbine generator system using different drive train models, IET Renew. Power Gener. 1 (2) (June 2007) 131-141.

[22] E. Nim. Wind turbine operational method, September 10 2009. US Patent App. $12 / 300,178$

[23] Andrea Staino, Biswajit Basu, Emerging trends in vibration control of wind turbines: a focus on a dual control strategy, Philos. Trans. R. Soc. Lond. A Math. Phys. Eng. Sci. 373 (2035) (2015).

[24] M. Tsili, S. Papathanassiou, A review of grid code technical requirements for wind farms, IET Renew. Power Gener. 3 (3) (Sept 2009) 308-332.

[25] Temesgen M. Haileselassie, Marta Molinas, Tore Undeland, et al., Multi-terminal vsc-hvdc system for integration of offshore wind farms and green electrification of platforms in the north sea, in: Nordic Workshop on Power and Industrial Electronics (NORPIE/2008), June 9-11, 2008, Espoo, Finland, Helsinki University of Technology, 2008.

[26] G. Giglia, M. Pucci, C. Serporta, G. Vitale, Experimental comparison of threephase distributed generation systems based on voc and dpc control techniques, in: 2007 European Conference on Power Electronics and Applications, Sept 2007, pp. 1-12.

[27] B.G. Liptak, Instrument Engineers' Handbook, in: Volume Three: Process Software and Digital Networks, CRC Press, 2002.

[28] The European Wind Energy Association EWEA. EWEA position on priority dispatch of wind power. 